\title{
ADUBAÇÃO EM VINHEDO ORGÂNICO DA CV. ISABEL UTILIZANDO CINZAS VEGETAIS E ESTERCO BOVINO ${ }^{1}$
}

\author{
RAFAEL PIVA ${ }^{2}$, RENATO VASCONCELOS BOTELHO ${ }^{3}$, CRISTIANO ORTOLAN ${ }^{4}$, \\ MARCELO MARQUES LOPES MÜLLER ${ }^{3}$, JACKSON KAWAKAMI $^{3}$
}

\begin{abstract}
RESUMO - A busca por uma viticultura mais sustentável exige o estudo de fontes alternativas de nutrientes que causem menor impacto ambiental. Neste contexto, este trabalho teve como objetivo avaliar o efeito de diferentes doses de cinzas vegetais e esterco bovino no desenvolvimento de videiras cv. Isabel. As doses utilizadas foram: $0 ; 750 ; 1.500$ e 2.250 g planta $^{-1}$ de cinzas vegetais e $0 ; 5$ e $10 \mathrm{~kg}_{\text {planta }}{ }^{-1}$ de esterco bovino, em esquema fatorial 4x3, com 12 tratamentos, cinco repetições e duas plantas por parcela. Nos dois primeiros ciclos de desenvolvimento vegetativo, foram avaliados o diâmetro dos ramos e o diâmetro do tronco e, no segundo ciclo, foi avaliado o índice de área foliar e realizadas as análises químicas de teores foliares de nutrientes. Houve efeitos positivos dos tratamentos para todas as variáveis estudadas, com mais evidência para as avaliações de índice de área foliar. De modo geral, para a maioria das variáveis, a dose de $5 \mathrm{~kg}$ planta $^{-1}$ de esterco teve os melhores resultados, acrescido de 750 ou $1.500 \mathrm{~g} \mathrm{planta-1}^{-1}$ de cinzas vegetais, ou o uso exclusivo de $10 \mathrm{~kg}_{\text {planta }}{ }^{-1} \mathrm{de}$ esterco bovino. No entanto, este último tratamento aumentou excessivamente o conteúdo de $\mathrm{N}$, o que poderia ser prejudicial às plantas. Concluiu-se que as duas fontes podem ser usadas de maneira a suprir as exigências nutricionais de plantas jovens de videira, necessitando, dependendo das condições de solo, de uma suplementação com potássio e cálcio.
\end{abstract}

Termos para indexação: Vitis labrusca L., adubação orgânica, nutrição mineral, agroecologia.

\section{FERTILIZATION IN ORGANIC VINEYARD CV. ISABEL USING WOOD ASH AND CATTLE MANURE}

\begin{abstract}
The search for a more sustainable viticulture requires the study of alternative sources that causes less environmental impact. This study aimed to evaluate the effect of different doses of wood ashes and cattle manure on the vegetative growth of grapevines cv. Isabella. The following doses were used: 0 , $750,1500,2250 \mathrm{~g} \mathrm{plant}^{-1}$ of wood ashes and 0,5 and $10 \mathrm{~kg} \mathrm{plant}^{-1}$ of cattle manure, in a factorial scheme $4 \times 3$, with 12 treatments, five replications and two plant per plot. In the first two vegetative cycles, it was evaluated the diameter of canes and trunk and; on the second cycle, it was evaluated the leaf area index and carried out the chemical analysis of nutrients leaf content. It was verified positive effects of treatments for all variables studied, with more evidence for the leaf area index evaluations. In general, for the most variables, the dose of $5 \mathrm{~kg} \mathrm{plant}^{-1}$ of cattle manure attained the best results, added to 750 or $1500 \mathrm{~g} \mathrm{plant}^{-1}$ of $^{2}$ wood ashes, or the exclusive use of $10 \mathrm{~kg} \mathrm{plant}^{-1}$ of cattle manure. Nevertheless, this last treatment increased excessively the $\mathrm{N}$ content, what could be harmful to plants. It was concluded that the two sources could be used to supply the nutritional exigencies of young vines, needing, depending on soil conditions, a supplement with potassium and calcium.
\end{abstract}

Index terms: Vitis labrusca L., organic fertilization, mineral nutrition, agroecology.

\footnotetext{
${ }^{1}$ (Trabalho 021-13). Recebido em: 03-01-2013. Aceito para publicação em: 07-06-2013.

${ }^{2}$ Eng. Agr. M. Sc. Departamento de Agronomia. Universidade Estadual do Centro-Oeste - Unicentro. R. Simeão Camargo Varella de Sá, 03, CEP 85040-080, Guarapuava-PR. Bolsista de Mestrado da Capes. E-mail: raffaelepiva@gmail.com.

${ }^{3}$ Eng. Agr. Dr. Prof. Adjunto. Departamento de Agronomia Unicentro. E-mails: rbotelho@unicentro.br, mmuller@unicentro.br; jkawakami@unicentro.br

${ }^{4}$ Acadêmico Agronomia Unicentro. E-mail: cristiano_ortolan@hotmail.com
} 


\section{INTRODUÇÃO}

A agricultura convencional, caracterizada pela monocultura, uso intensivo do solo e controle químico de pragas e doenças, acarretou homogeneizações espacial, temporal e genética da maioria dos agroecossistemas. No Brasil, este sistema foi amplamente difundido nas últimas três décadas, em consequência do crescimento da demanda de produtos agrícolas. Advindo dessa homogeneidade do agroecossistema e das práticas mencionadas, a agricultura convencional é responsável por notáveis alterações nas comunidades biológicas e nos ciclos biogeoquímicos de nutrientes, denominadas genericamente como impactos ambientais. Atualmente, a incorporação de elementos, tais como a necessidade de aumentar a sustentabilidade produtiva dos sistemas e a pressão de grupos consumidores, tem forçado a reavaliação de tais modelos convencionais de produção e a proposição de sistemas mais sustentáveis e causadores de menor impacto ambiental (FADINI; LOUSADA, 2001).

Seguindo este anseio da população por sistemas de produção mais sustentáveis, o mercado de produtos orgânicos no Brasil cresceu, em 2010, cerca de $40 \%$ e movimentou o equivalente a 350 milhões de reais. A área destinada à produção agropecuária orgânica no Brasil é de 800.000 hectares e engloba em torno de 190.000 produtores, sendo que deste total, $90 \%$ são constituídos por pequenas propriedades (BRASIL, 2011).

Neste sistema sustentável, prioriza-se a adubação orgânica, que apresenta como principais características a melhoria das propriedades físicas, químicas e biológicas do solo. Os nutrientes presentes em adubos orgânicos, especialmente o nitrogênio e o fósforo, possuem liberação mais lenta do que aqueles provenientes dos fertilizantes químicos, pois são dependentes da mineralização da matéria orgânica, proporcionando disponibilidade ao longo do tempo, o que favorece muitas vezes seu aproveitamento (GLIESSMAN, 2000).

A cinza vegetal é um resíduo proveniente da queima da madeira que, dependendo de sua origem, pode apresentar elevados teores de $\mathrm{K}, \mathrm{P}, \mathrm{Ca}$ e $\mathrm{Mg}$, e pode ser utilizada como suplemento nutricional, dependendo do balanço apresentado pelo solo e das exigências da cultura (VOUNDINKANA et al., 1998; ZHANG et al., 2002).

A aplicação de cinza vegetal em plantios agrícolas apresenta-se como uma importante oportunidade de restituição de parte dos nutrientes removidos pelas culturas. A reciclagem das cinzas reduz a necessidade do uso de fertilizantes comerciais, contribuindo com a redução da acidificação do solo e com o aumento do suprimento de cálcio (ZIMMERMANN; FREY, 2002; SOFIATTI et al., 2007).

Sobre as principais vantagens do uso de adubos orgânicos, Damatto Júnior et al. (2006) observaram que, após quatro meses da aplicação de um composto de serragem e esterco bovino na adubação da bananeira, houve um incremento no $\mathrm{pH}$ do solo e nos teores de matéria orgânica, fósforo e cálcio, além do incremento da soma de bases, da capacidade de troca catiônica e da saturação por bases.

Muitas indústrias utilizam plantas como biomassa, entre elas as indústrias de cerâmica, celulose e papel. Um dos compostos formados após utilização da madeira é a cinza, que muitas vezes é deixada de lado e depositada em aterros, diminuindo assim a vida útil dos mesmos (PRADO et al., 2002).

Neste contexto, objetivou-se avaliar os efeitos de doses de cinzas vegetais e de esterco bovino na implantação e na manutenção da cultura da videira cv. Isabel em Guarapuava, região centro-sul do Estado do Paraná.

\section{MATERIAL E MÉTODOS}

O experimento foi realizado em vinhedo comercial, em Guarapuava-PR. As coordenadas geográficas locais são: $25^{\circ} 23^{\prime} 36^{\prime \prime} \mathrm{S}$ e $51^{\circ} 27^{\prime} 19^{\prime}$ 'O, e $1.120 \mathrm{~m}$ de altitude. O clima é classificado como subtropical mesotérmico-úmido $(\mathrm{Cfb})$, sem estação seca, com verões frescos e inverno moderado (IAPAR, 2000). O solo da área experimental é um Latossolo Bruno distroférrico.

Para o experimento, foram usados esterco bovino curtido de animais alimentados a pasto e cinzas vegetais provenientes de uma termoelétrica do município de Guarapuava-PR. A área era usada anteriormente para produção de grãos, e, antes da implantação do experimento, foi realizada a análise química do solo e dos materiais usados na adubação de implantação (Tabelas 1 e 2). A calagem foi realizada previamente em área total para atingir $80 \%$ da saturação de bases e, para incorporação do calcário, foi feita uma aração profunda e posterior gradagem.

O delineamento experimental foi em blocos casualizados, em esquema fatorial $4 \times 3$, totalizando 12 tratamentos, cinco repetições e parcela experimental constituída por duas plantas. $\mathrm{O}$ fator primário foi definido pelas seguintes doses de cinzas vegetais: $0 ; 750 ; 1.500$ e $2.250 \mathrm{~g} \mathrm{planta}^{-1}$. O fator secundário foi composto pelas seguintes doses de esterco bovino: $0 ; 5$ e $10 \mathrm{~kg} \mathrm{planta}^{-1}$. Estas fontes de nutrientes foram aplicadas em pré-plantio, em covas e em cobertura, na faixa de plantio, no ano seguinte, em única parcela. 
As covas possuíam medidas de 40x40x40cm, onde as fontes de nutrientes foram misturadas ao solo no momento do plantio. As mudas de videira da cv. Isabel, enxertadas sobre o porta-enxerto 'Paulsen 1103', foram plantadas em 14-09-2009, no espaçamento $1,5 \times 2,5 \mathrm{~m}$.

Após o plantio, as mudas foram podadas a 1 metro de altura e sustentadas em espaldeira com dois braços permanentes. As práticas culturais seguiram aquelas preconizadas para sistema orgânico (BRASIL, 2007). Para o manejo de pragas e doenças, foram realizadas pulverizações mensais com calda bordalesa.

No final do primeiro ciclo, em maio de 2010, os dois braços principais foram avaliados quanto ao seu diâmetro na base, e no segundo ciclo, os ramos terciários, com auxílio de um paquímetro digital. O diâmetro do tronco foi medido logo acima do enxerto, no momento do plantio e nos dois invernos seguintes.

Para a estimativa do índice de área foliar ( $\mathrm{m}^{2}$ de área foliar por $\mathrm{m}^{2}$ de superfície do terreno), primeiramente se realizou um estudo para o estabelecimento da melhor correlação entre medições não destrutivas e a área foliar, mediante método adaptado de Carbonneau (1976). Foram coletadas 50 folhas do vinhedo, de tamanhos variáveis, porém fora da área experimental. As folhas, dispostas em cartolina branca, foram fotografadas com câmera digital e, em seguida, digitalizadas, e sua área, determinada a partir de sua imagem com o programa Image $J^{\circledR}$. Para cada folha, foram feitas medições das duas nervuras principais a partir das quais se estabeleceram correlações do comprimento de uma ou da somatória das duas nervuras centrais com a área determinada de cada folha.

Devido ao coeficiente de determinação encontrado para a relação entre área foliar e comprimento de apenas uma nervura central $(r=92,30 \%)$, estabeleceu-se para a estimativa da área foliar a equação $y=1,0033 x^{2}$, em que: $y$ é a área foliar estimada, e $x$ o comprimento da nervura central esquerda (Figura 1).

Para cada parcela experimental, foi medido o comprimento de uma das nervuras principais de $30 \%$ da folhas de dois ramos de cada planta, em dezembro de 2010. Com estes resultados, estimou-se a área foliar de cada ramo, e posteriormente de toda a planta, a partir do número total de ramos. Em seguida, calculou-se o índice de área foliar, dividindo-se a área foliar total estimada de cada planta pela sua área ocupada no terreno.

No segundo ano, foi realizada a análise química foliar, coletando-se cinco folhas recém-maduras de cada planta, na fase fenológica de pleno floresci- mento. As análises de tecido foliar foram realizadas segundo Malavolta (1997): P, K, Ca, Mg, S, Fe, Cu, Zn e Mn, extraídos por digestão nitroperclórica, e sua determinação,realizada segundo EMBRAPA (2009) por espectrofotometria de absorção atômica (EAA).

Os resultados foram submetidos à análise de variância, estudando-se a interação entre os fatores. Quando significativo, realizaram-se regressão polinomial e teste de Tukey, ao nível de 5\% de probabilidade de erro, pelo programa estatístico SISVAR 5.0 (FERREIRA, 2000).

\section{RESULTADOS E DISCUSSÃO}

O diâmetro dos ramos apresentou, no primeiro ano, efeito quadrático para as doses crescentes de cinzas dos tratamentos sem esterco e com $5 \mathrm{~kg}$ de esterco bovino, com estimativa para máximo diâmetro dos ramos, para a combinação de 1.100 $\mathrm{g}$ de cinza vegetal e $5 \mathrm{~kg}$ de esterco bovino. Com $10 \mathrm{~kg}$ de esterco, a regressão não foi significativa, mas os valores de diâmetro para estes tratamentos foram elevados (Figura 2A). No segundo ano, houve efeito linear positivo em função das doses de cinzas vegetais para a dose de $5 \mathrm{~kg}$ de esterco bovino, sendo que a dose de $10 \mathrm{~kg}$ de esterco apresentou as maiores médias de diâmetro de ramo, sem haver significância para regressão, em função das doses de cinzas vegetais (Figura 2B).

Damatto Júnior et al. (2005) estudaram os efeitos do uso do esterco bovino na adubação do maracujazeiro e observaram os melhores resultados no desenvolvimento das plantas e na qualidade de frutos, com $5 \mathrm{~kg}$ de esterco bovino por planta.

As medidas de diâmetros observadas comprovam o bom desenvolvimento das plantas, durante os dois ciclos. Silva et al. (2010) encontraram valores semelhantes de diâmetro estudando a cultivar BRS Violeta, em 17 diferentes porta-enxertos, em condições subtropicais, no oeste paranaense, onde os valores variaram de $0,98 \mathrm{~mm}$ com o porta-enxerto 'VR 043-43' e atingiram até 7,13 $\mathrm{mm}$ com o 'Rupestris Du Lot', avaliados 9 meses após o plantio.

Para o diâmetro do tronco, no primeiro ano, houve efeito quadrático em função de doses crescentes de cinzas vegetais para os tratamentos com 5 $\mathrm{kg}$ de esterco bovino (Figura 3A). A dose de cinzas vegetais para o máximo diâmetro do tronco foi estimado em 1.013,3 $\mathrm{g} \mathrm{planta}^{-1}$. No segundo ano, não houve efeito de interação, mas as doses de esterco bovino apresentaram efeito significativo. A dose de $10 \mathrm{~kg}$ foi superior à dose de $0 \mathrm{~kg}$ de esterco bovino, mas não se diferiu da dose de $5 \mathrm{~kg}$ (Figura 3B).

Para o índice de área foliar, houve efeito 
linear positivo para doses crescentes de cinzas vegetais, para os tratamentos com 5 e $10 \mathrm{~kg}$ de esterco bovino. O acréscimo foi de cerca de $35 \%$ para a dose de $2.250 \mathrm{~g}$ de cinzas vegetais em relação à não aplicação de cinzas.

Outros autores também verificaram efeito positivo da aplicação de cinzas no crescimento das plantas, atribuindo este efeito às melhorias das características químicas do solo. Park et al. (2005) desenvolveram pesquisa com cinzas de madeira durante 3 anos, nas doses de $0 ; 10$ e $20 \mathrm{t} \mathrm{ha}^{-1} \mathrm{em}$ salgueiro (Salix purpurea), e verificaram aumento significativo no $\mathrm{pH}$ do solo na camada de $0-10 \mathrm{~cm}$, de 6,1 na dose-controle para 6,9 e 7,1 nas duas dosagens. A cinza ainda aumentou, significativamente, o fósforo extraível e a concentração de potássio, cálcio e magnésio no solo. Além disso, as hastes apresentaram maior comprimento em relação ao controle. Darolt et al. (1993), por sua vez, testaram diferentes quantidades de cinza na nutrição de alface e verificaram ganhos significativos na produção, sendo que os maiores ocorreram nas quantidades de 10 e $15 \mathrm{t} \mathrm{ha}^{-1}$, enquanto, nas doses de 20 e $30 \mathrm{t} \mathrm{ha}^{-1}$, os resultados foram inferiores.

Os resultados das análises de nutrientes nas folhas apresentaram diferenças significativas para os elementos nitrogênio, potássio e ferro, com efeito apenas das doses de esterco bovino. Independentemente das doses de cinzas vegetais, os teores de $\mathrm{N}$ e K foram superiores para a dose de $10 \mathrm{~kg}_{\text {planta }}{ }^{-1}$, diferindo-se apenas dos tratamentos em que não foi aplicado o esterco. Para o teor de Fe nas folhas, as doses de 5 e $10 \mathrm{~kg}$ planta $^{-1}$ foram superiores ao tratamento em que não foi aplicado esterco bovino.

De maneira geral, para todas as médias, verificou-se que o teor de $\mathrm{N}$ foi acima do normal, os teores de $\mathrm{K}$ e $\mathrm{Ca}$ foram abaixo do normal, e todos os demais elementos analisados (P, Mg, Fe, Mn e Zn) apresentaram teores interpretados como normais (CQFS-SC/RS, 2004). O desequilíbrio nutricional verificado nas videiras pode estar relacionado à relação não ideal dos elementos $\mathrm{K}: \mathrm{Ca}: \mathrm{Mg}$ no solo, principalmente devido a um teor muito elevado de magnésio por um uso indiscriminado de calcário dolomítico, comum na região de Guarapuava-PR. O antagonismo, definido com as interações entre íons de similar tamanho e valência, é frequentemente a causa de deficiências, porque os sítios de ligação na célula não podem distinguir as diferenças entre estes íons (MARSCHNER, 1995).

Segundo Oliveira et al. (2001), a falta de resposta da soja à aplicação de maiores quantidades de potássio pode estar relacionada com suas interações com $\mathrm{Ca}$ e $\mathrm{Mg}$, ou seja, com a calagem. Mafra et al. (2011), em estudo sobre nutrição e nutrição de videiras Cabernet Sauvignon, observaram associação entre teores dos nutrientes no solo e no tecido foliar, destacando-se a correlação linear negativa entre o teor de $\mathrm{K}$ extraível e o teor de $\mathrm{Mg}$ no tecido, assim como entre o teor de Mg trocável do solo e o teor de $\mathrm{K}$ no tecido vegetal, evidenciando antagonismo entre estes dois nutrientes na absorção pela planta.

A ausência de diferenças encontradas para os teores foliares de nutrientes entre as videiras tratadas com diferentes doses de cinzas vegetais pode estar relacionada, em parte, a um efeito de diluição, tendo em vista o resultado significativo dos diferentes tratamentos nas avaliações de crescimento da planta, como diâmetro do tronco, diâmetro de ramos e índice de área foliar. De qualquer forma, pôde-se verificar a necessidade de complementação com alguma fonte de potássio, como, por exemplo, o uso de sulfato de potássio, permitido na produção orgânica, como fonte suplementar.

Com os resultados deste trabalho, ficou evidente que as cinzas vegetais e o esterco bovino podem ser usados como alternativa na adubação da videira, principalmente pela fácil aquisição, baixo custo e contribuição ao meio ambiente pelo aproveitamento dos resíduos agroindustriais. Muitas vezes, os materiais usados nesse tipo de adubação são descartados ou deixados de lado, pois, além de perder seu potencial como adubo, podem contaminar determinados locais na água ou no solo (PRADO et al., 2002). 
TABELA 1- Características químicas (teores totais) do solo da área de implantação do experimento com videiras cv. Isabel (Guarapuava-PR, 2009).

\begin{tabular}{|c|c|c|c|c|c|c|c|c|c|c|}
\hline \multirow{2}{*}{ Camada $(\mathrm{cm})$} & $\mathrm{pH}$ & M.O & $P_{\text {melich }}$ & $\mathrm{H}+\mathrm{Al}$ & K & $\mathrm{Ca}$ & $\mathrm{Mg}$ & SB & CTC & \multirow{2}{*}{$\mathrm{V} \%$} \\
\hline & $\mathrm{CaCl}_{2}$ & $\mathrm{~g} / \mathrm{kg}$ & $\mathrm{mg} / \mathrm{dm}^{3}$ & \multicolumn{6}{|c|}{$\mathrm{cmol}_{\mathrm{c}} / \mathrm{dm}^{3}$} & \\
\hline $0-20$ & 5,3 & 38,9 & 10,6 & 4,63 & 0,53 & 6,1 & 3,5 & 10,13 & 14,76 & 68,7 \\
\hline $20-40$ & 5,3 & 37,6 & 10,1 & 4,42 & 0,51 & 6,0 & 3,4 & 9,91 & 14,33 & 68,1 \\
\hline
\end{tabular}

TABELA 2 - Características químicas (teores totais) dos materiais usados na adubação de implantação no experimento com videiras cv. Isabel (Guarapuava-PR, 2009).

\begin{tabular}{ccccccccc}
\hline & $\mathrm{N}$ & $\mathrm{P}_{2} \mathrm{O}_{5}$ & $\mathrm{~K}_{2} 0$ & $\mathrm{Ca}$ & $\mathrm{Mg}$ & $\mathrm{S}$ & $\mathrm{MO}$ & $\mathrm{C}$ \\
\cline { 2 - 8 } & \multicolumn{7}{c}{ Porcentagem na matéria seca } \\
\hline Esterco & 2,66 & 2,40 & 0,75 & 1,09 & 0,67 & 0,70 & 57,0 & 31,7 \\
Cinza & 0,28 & 0,49 & 0,23 & 0,75 & 0,15 & 0,25 & 17,0 & 9,40 \\
\hline
\end{tabular}

TABELA 3 -Teores de nutrientes em folhas de videiras cv. Isabel adubadas com diferentes doses de esterco bovino e cinzas vegetais (Guarapuava-PR, 2011).

\begin{tabular}{ccccccccccc}
\hline $\begin{array}{c}\text { Esterco } \\
\left(\mathrm{kg} \mathrm{planta}^{-1}\right)\end{array}$ & $\mathbf{N}$ & $\mathbf{P}$ & $\mathbf{K}$ & $\begin{array}{c}\mathbf{C a} \\
\mathbf{g ~ k g}^{-1}\end{array}$ & $\mathbf{M g}$ & $\mathbf{S}$ & $\mathbf{M n}$ & $\mathbf{C u}$ & $\begin{array}{c}\mathbf{F e} \\
\mathbf{m g ~ k g}^{-1}\end{array}$ & $\mathbf{Z n}$ \\
\hline 0 & $42,5 \mathrm{~b}$ & 2,12 & $5,43 \mathrm{~b}$ & 14,5 & 4,43 & 2,00 & 123,6 & 477,3 & $118,5 \mathrm{a}$ & 45,2 \\
5 & $42,6 \mathrm{~b}$ & 2,06 & $5,81 \mathrm{ab}$ & 13,5 & 4,37 & 2,00 & 140,3 & 463,8 & $98,43 \mathrm{~b}$ & 43,0 \\
10 & $47,9 \mathrm{a}$ & 2,18 & $6,56 \mathrm{a}$ & 12,8 & 4,37 & 2,06 & 98,25 & 471,6 & $97,31 \mathrm{~b}$ & 45,1 \\
\hline Média & 44,3 & 2,12 & 5,93 & 13,6 & 4,39 & 2,02 & 120,7 & 470,9 & 104,7 & 44,3 \\
\hline $\begin{array}{c}\text { Cinzas } \\
(\text { g planta }\end{array}$ & & & & & & & & & & \\
0 & 46,8 & 2,08 & 5,58 & 14,0 & 4,41 & 2,00 & 134,4 & 455,5 & 103,8 & 44,0 \\
750 & 42,4 & 2,16 & 6,25 & 13,4 & 4,33 & 2,00 & 111,5 & 489,8 & 106,2 & 44,3 \\
1.500 & 43,1 & 2,08 & 6,16 & 13,4 & 4,25 & 2,00 & 124,0 & 480,1 & 106,2 & 46,0 \\
2.250 & 45,1 & 2,16 & 5,75 & 14,5 & 4,58 & 2,08 & 113,0 & 458,3 & 102,2 & 43,5 \\
\hline Média & 44,3 & 2,12 & 5,93 & 13,8 & 4,39 & 2,02 & 120,7 & 470,9 & 104,6 & 44,4 \\
\hline
\end{tabular}

Médias seguidas pela mesma letra na coluna não diferem entre si, pelo teste de Tukey, a 5\% de probabilidade de erro.

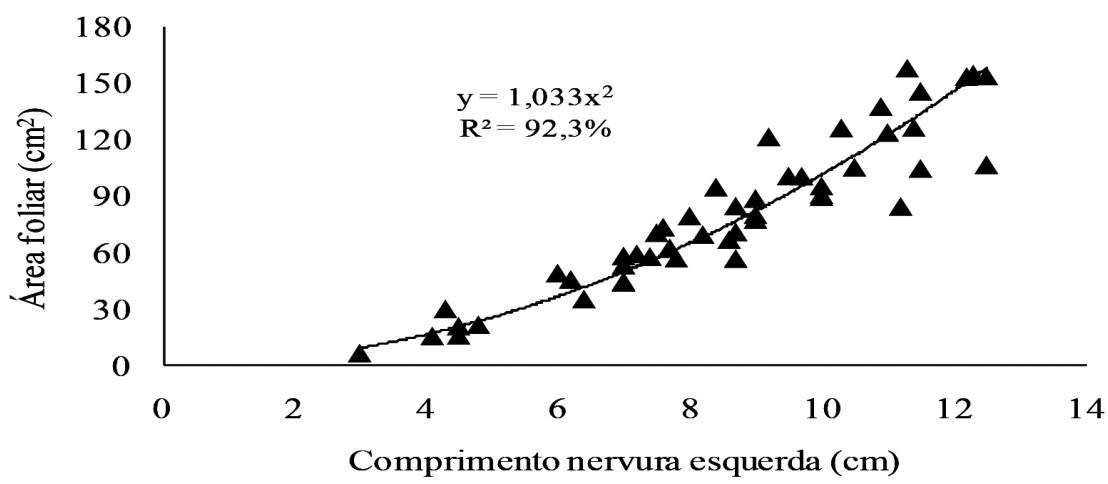

FIGURA 1- Relação entre comprimento da nervura esquerda e área foliar de folhas de videiras cv.Isabel

(Guarapuava-PR, 2010) * significativo a 5\% de probabilidade de erro. 

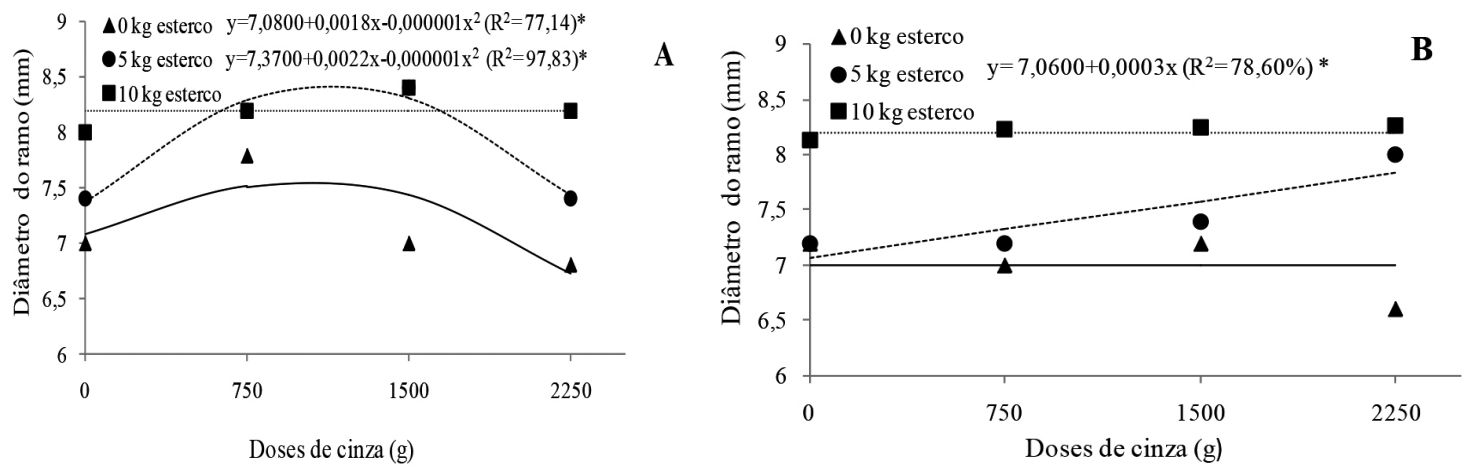

FIGURA 2- Diâmetro de ramos de videiras cv. Isabel em função de doses de cinzas vegetais e esterco bovino, nos ciclos vegetativos de 2009/2010 (A) e 2010/2011 (B) Guarapuava-PR.

* significativo a $5 \%$ de probabilidade de erro.
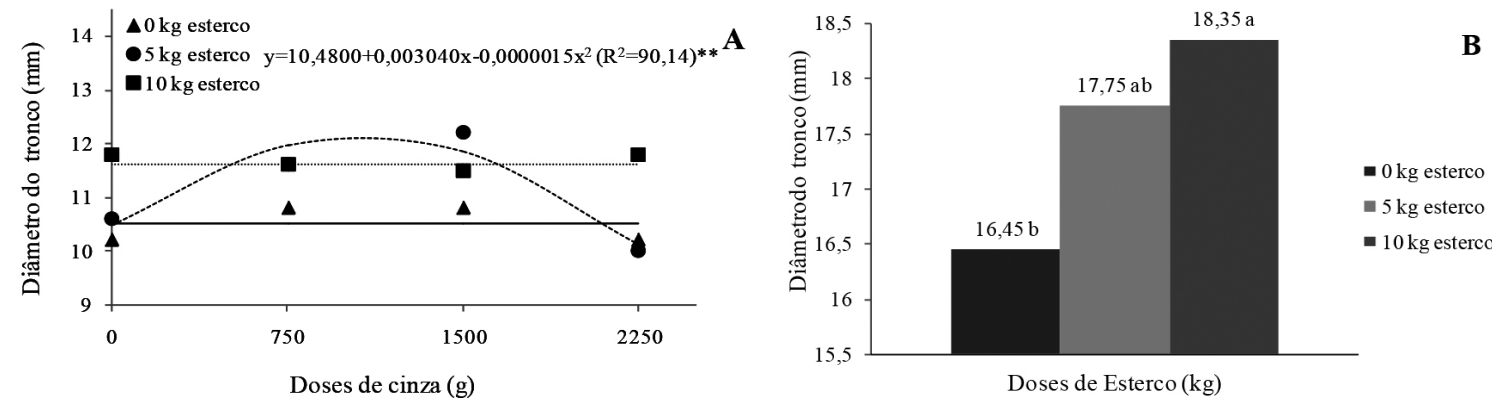

FIGURA 3- Diâmetro de tronco de videiras cv. Isabel em função de doses de cinzas vegetais e esterco bovino no inverno de 2010 (A) e em função de doses de esterco no inverno de 2011 (B). Guarapuava-PR, 2011.

** significativo a $1 \%$ de probabilidade de erro. Letras iguais não diferem pelo teste de Tukey, a 5\% de probabilidade de erro.

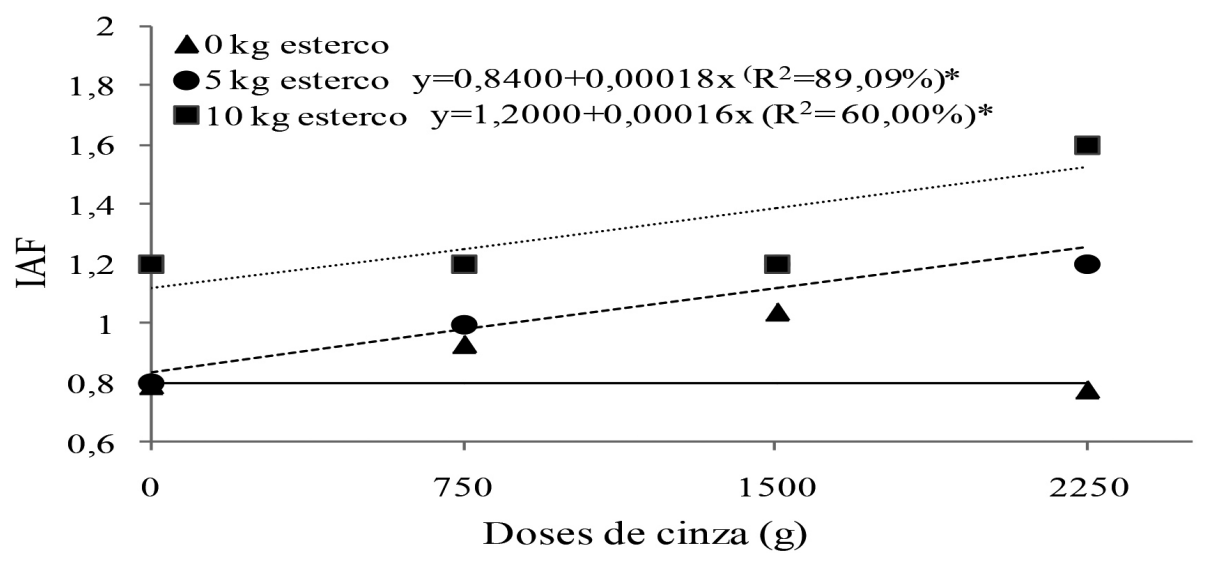

FIGURA 4- Índice de área foliar de videiras cv. Isabel em função de doses de cinzas vegetais e de esterco bovino, no segundo ciclo vegetativo.Guarapuava-PR, 2011. * significativo a 5\% de probabilidade de erro. 


\section{CONCLUSÕES}

De maneira geral, para a maioria das variáveis avaliadas, os melhores efeitos no desenvolvimento vegetativo de videiras cv. Isabel foram verificados com o uso de $10 \mathrm{~kg}$ planta $^{-1}$ de esterco bovino, de maneira isolada ou com $5 \mathrm{~kg}$ de esterco bovino acrescido de cinzas vegetais, entre 750 e 1.500 g planta $^{-1}$. No entanto, o uso de $10 \mathrm{~kg}$ de esterco bovino elevou, significativamente, o teor de $\mathrm{N}$ das folhas, o que pode ser considerado um problema em algumas situações, devido ao excesso desse elemento.

A análise química das folhas mostrou que os elementos ficaram dentro do normal, em sua maioria, exceto para o excesso de $\mathrm{N}$ e a deficiência de $\mathrm{K}$ e $\mathrm{Ca}$, que exigiriam a complementação com outras fontes de nutrientes, para um melhor equilíbrio entre os elementos no solo.

\section{AGRADECIMENTOS}

Agradecimentos à CAPES, pela concessão de bolsa de mestrado ao primeiro autor, e ao CNPq e à Fundação Araucária, pelo apoio financeiro para o desenvolvimento desta pesquisa.

\section{REFERÊNCIAS}

BRASIL. Ministério da Agricultura, Pecuária e Abastecimento. Decreto $N^{\circ} 6.323$, de 27 de dezembro de 2007. 2007. Disponível em: < http://www.agricultura.gov.br/legislacao >. Acesso em: 10 fev. 2010.

BRASIL. Ministério da Agricultura, Pecuária e Abastecimento. Mercado interno de orgânicos cresce 40\% em 2010. 2011. Disponível em: $\leq$ http://www. agricultura.gov.br>. Acesso em: 04 fev.2011.

CARBONNEAU, A. Analyse de la croissance dês feuilles du sarment de vigne: estimation de sa surface foliaire par echantillonnage. Connaissance de la Vigne et du Vin, Talance, v.10, n.2, p.141-159, fev. 1976.

CQFS - Comissão de Química e Fertilidade do Solo-RS/SC. Manual de adubação e de calagem para os Estados do Rio Grande do Sul e de Santa Catarina. 10.ed. Porto Alegre: SBCS-Núcleo Regional Sul, 2004. 400p.
DAMATTO JÚNIOR, E.R.; LEONEL, S.; PEDROSO, C.J. Adubação orgânica na produção e qualidade de frutos de maracujá-doce. Revista Brasileira de Fruticultura, Jaboticabal, v.27, n.1, p.188-190, 2005.

DAMATTO JÚNIOR, E.R.; VILLAS BOAS, R.L.; LEONEL, S.; FERNANDES, D.M. Alterações em propriedades de solo adubado com doses de composto orgânico sob cultivo de bananeira. Revista Brasileira de Fruticultura, Jaboticabal, v.28, n.3, p.546-549, 2006.

DAROLT, M.R.; BLANCO NETO, V.; ZAMBON, F.R.A. Cinza vegetal como fonte de nutrientes e corretivo de solo na cultura da alface. Horticultura Brasileira, Viçosa, MG, v.11, p.38-40, 1993.

EMBRAPA. Manual de análises químicas de solos, plantas e fertilizantes. 2.ed. Brasília: Embrapa Informação Tecnológica, 2009. 627p.

FADINI, M.A.M.; LOUZADA, J.N.C. Impactos ambientais da agricultura convencional. Informe Agropecuário, Belo Horizonte, v.22, n.213, p.2429, 2001.

FERREIRA, D. F. Sisvar: a computer statistical analysis system. Ciência e Agrotecnologia, Lavras, v. 35, n.6, p.1039-1042, 2000.

GLIESSMAN, S. R. Agroecology: ecological processes in sustainable agriculture. Boca Raton: Lewis Publishers, 2000. 357 p.

IAPAR - Instituto Agronômico do Paraná. Cartas climáticas do Paraná. Versão 1.0. Londrina: IAPAR, 2000. CD-ROM.

MAFRA, M.S.H.; CASSOL, P.C.; MIQUELLUTI, D.J.; ERNANI, P.R.; GATIBONI, L.C.; FERREIRA, E.Z.; BARROS, M.; ZALAMENA, J.; GROHSKOPF, M.A. Atributos químicos do solo e estado nutricional de videira Cabernet Sauvignon (Vitis vinifera L.) na Serra Catarinense. Revista de Ciências Agroveterinárias, Lages, v.10, n.1, p.44-53, 2011.

MALAVOLTA, E. Avaliação do estado nutricional das plantas: princípios e aplicações. 2.ed. Piracicaba: POTAFÓS, 1997. 319p.

MARSCHNER, H. Mineral nutrition of higher plants. San Diego: Academic Press, 1995. 889p. 
OLIVEIRA, F.A.; CARMELLO, Q.A.C.; MASCARENHAS, H.A.A. Disponibilidade de potássio e suas relações com cálcio e magnésio em soja cultivada em casa de vegetação. Scientia Agricola, Piracicaba, v.58, n.2, p.329-335, 2001.

PARK, B.B.; YANAI, R.D.; SAHM, J.M.; LEE, D.K.; ABRAHAMSON, L.P. Wood ash effects on plant and soil in a willow bioenergy plantation. Biomass and Bioenergy, Oxford, v.28 p.355-365, 2005.

PRADO, R.M.; CORRÊA, M.C.M.; NATALE, W. Efeito da cinza da indústria de cerâmica no solo e na nutrição de mudas de goiabeira. Acta Scientiarum, Maringá, v.24, n.5, p.1.493-1.500, 2002.

SILVA, T.P.; PIO, R.; SALIBE, B.A.; DALASTRA, I.M.; STAMGARLIN, J.R.;KUHN, O.J. Avaliação de porta-enxertos de videira em condições subtropicais. Bragantia, Campinas, v.69, n.1, p.93-97, 2010.
SOFIATTI, V.; LIMA, R. L. S.; GOLDFARD, M.; BELTRÃO, N. E. M. Cinza de madeira e lodo de esgoto como fonte de nutrientes para o crescimento do algodoeiro. Revista de Biologia e Ciências da Terra, Campina Grande, v.7, n.1, p.144-152, 2007.

VOUNDINKANA, J. C.; DEMEYER, A.; VERLOO, M. G. Availability of nutrients in wood ash amended tropical acid soils. Environmental Technology, London, v. 19, p. 1213-1221, 1998.

ZHANG, F. S.; YAMASAKI, S.; NANZYO, M. Waste ashes for use in agricultural production: I. Liming effect, contents of plants nutrients and chemical characteristics of some metals. Science of the Total Environment, Amsterdam, v.284, p.215225, 2002.

ZIMMERMANN, S.; FREY, B. Soil respiration and microbial properties in an acid forest soil: effects of wood ash. Soil Biology \& Biochemistry, Elmsford, p. 1-11, 2002. 